\title{
LOIE FULLER EN MÉXICO
}

\author{
Herrol Dallal
}

De acuerdo a ciertas páginas de una enciclopedia norteamericana, ' Loie Fuller nació en Fullersburg, Illinois en 1862. Fuller situó siempre el acontecimiento en 1870 . A su muerte, acaecida en 1928, las dos fechas de su nacimiento no importaban tanto: "La Loie" había contribuido con su brillante grano de arena a llenar toda una época del mundo de los espectáculos del Eje Nueva York-París. Y lo que es más importante: había abierto enormes posibilidades técnicas y artísticas para los sorprendidos habitantes del mundo occidental, tanto de la pre-guerra primera como de la entre-guerra mundial En 1928 Loie Fuller tenía ganada la inmortalidad de los inconformes y de los inquietos, de los que saquean sus propias reservas de pureza y fantasía para (en el caso de "La Loie" la expresión resulta literal) dar a luz una nueva concepción de las cosas, tratándose aqui de las cosas del teatro, de la danza y de las artes del espectáculo

Loie Fuller adquiere esta aún desconocida importancia por dos razones: 1) libera antes que nadie y generaliza la dramatización de las emociones por medio de los movimientos más naturales y sencillos del cuerpo (para conseguirlo se apoya en piezas musicales cultas o importantes); 2) aplica, utiliza por primera vez y en algunas instancias inventa algunos procedimientos de la técnica de la iluminación de los escenarios que habrían de hacerse comunes en las modernas artes del espectáculo o que propondrian imágenes insospechadas para la escena contemporánea

Seguramente la visita de Loie Fuller a México en enero de 1897 produjo influencias notables o registrables. Sus cinco presentaciones ante el públiço mexicano vinieron acompañadas por una fama recientemente adquirida, toda vez que "el baile que pronto después debía darle fama universal"" se había conformado en el espacio escénico de una manera casual apenas en 1891. Sus luminosas glorias, sin embargo, tardaron algún tiempo en ser reconocidas pues Loie Fuller era actriz de teatro y su paso hacia la danza es resultado del propio arrobo ante un vestido de seda. Los primeros éxitos de su espectáculo dancístico son "modestos" y debe viajar por Alemania y Francia y penetrar en el mundo del Folies-Bergèr e para que empresarios, críticos y espectadores se percaten de la importancia de su talento De todas formas, Loie Fuller convence al público entrándole por el sentido de la vista, la vía de acción más lícita y auténtica de la danza, la pintura y la arquitectura.

Para 1897, la lista de sus cor eografías no era demasiado extensa Con todo, títulos como Serpentine (la que la lanzara al mundo de la danza intempestiva-

1 The Dame Emblopaler, Simon and Schuster, New York, 2a ed, 1967

${ }^{2}$ El Universal, 12 Enero de 1897 
mente en 1891), Butterfly (1892), Mirror (1893), The Flower (1893), The Rainbow (1893), Salomé (1895), Fire Dance (1895) dan fe del ahínco con el que Loie había trabajado ante su nuevo descubrimiento: la combinación luz-oscuridad y el juego de cuerpo y vestuario con esta combinación Los mismos títulos de las obras indican las características poco habituales de la naturaleza de sus danzas. En México, los ávidos lectores de las crónicas periodísticas de principios del Porfiriato podian sentirse atraídos con la suficiente antelación cuando se anticipaban ciertos detalles técnicos de la presentación de Loie, como el que se refiere al hecho de que "para los efectos de luz que se necesita producir en los bailes, va a haber necesidad de quitar parte del piso del foro sustituyéndolo con cristales". Estos y otros datos, como el número de empleados especializados en electricidad que acompañaban a "La Loie", redundaron en un éxito total, antecedente del que por muchas partes del mundo obtuvo la innovadora artista.

Las características profesionales y personales de Loie Fuller indican méritos y condiciones interesantes. Sus padres eran gente de teatro; violinista él, y de los pobres, al grado de que Loie hizo su debut a las seis semanas de nacida actuando en un papel silencioso e inmóvil Como dicen que muchos años más tarde habría de decir Judy Garland de ella misma, Loie Fuller salió al escenario intempestivamente, a los dos y medio (otros sitúan el acontecimiento a los cuatro años de edad), antes de que su madre pudiese impedirlo, para "recitar" una canción tradicional. Tal parece que los impulsos histriónicos de los infantes del viejo music-hall norteamericano eran dificiles de obstaculizar. Pero durante muchos años, a lo largo de toda su vida, "La Loie" se habia de referir a otro elemento contundente e impresionante, también vinculado a los inicios de su carrera: el frío que la caló hasta los huesos. En efecto, había nacido en el cuarto contiguo a un bar de mala muerte en donde se localizaba la única estufa digna de ese nombre para acoger a la recién nacida. Así hablaba la Fuller describiendo algo semejante a su destino pues todas sus revoluciones, sus cambios, sus persecuciones se localizan en ese prurito muy suyo de iluminar al cuerpo humano, de rodearlo de una atmósfera de luz, de crear un ambiente luminoso, cálido, que lo conduzca a mostrar figuras de una manera distinta a todas las conocidas. Y en este sentido, "La Loie" no habría de ceder un ápice en sus demandas, al grado de establecer contactos personales con los esposos Curie y con Flammarion. Sus adquisiciones de conocimiento y sus aplicaciones serían tan profundas como su avidez de calor. A pesar de sus artificios y tinglados imprevistos, "La Loie" era capaz de inventar métodos que a partir de sus trabajos llenaron los escenarios del mundo de nuevas visiones y técnicas

Durante los años anteriores a 1891, Loie Fuller es una de tantas actrices primerizas, entregada en cuerpo y alma al mundo del teatro. Por su mente no transita ninguna concepción de la danza, toda vez que es un personaje regordete y en su vida cotidiana hasta cierto punto extravagante. Por esta época ya 
posee esa enorme simpatía que le hará accesibles los recovecos más inhóspitos del espectáculo norteamericano, que la mantendría al margen del estrellato artificial pero que al mismo tiempo le permitirá organizar más tarde un equipo funcional de técnicos incondicionales. En los años 86 y 87 transita por varias obras teatrales de segunda categoría kasta que en cierta ocasión sobreviene por casualidad, accidentalmente, cierto juego de luces entre la luminosidad del escenario ( $i$ o fue en su camerino?) y un enorme vestido de seda que se probará "sólo por variar la rutina". Alguien (¿del público, del staff?) gritó: "Es una mariposá; es una orquidea". Y las fauces de la curiosidad quedaron abiertas delante de "La Loie", con las una y mil gamas de seda y luz que en aquel momento irrumpían a una nueva realidad escénica gracias a la inventiva de una actriz. Se realizaba su sueño de oro: vestimentas exóticas, pies descalzos, el azar circunstancial de las luces, los colores que desde aquel momento la acompañarían. Sin saber a ciencia cierta cuál era la naturaleza de la danza, la Fuller descubría por su humilde lado, por su auténtica veta, por su intransigente camino lo que tantas elucubraciones y tantos ejercicios neoclásicos descubriera más tarde Isadora Duncan en salones burgueses y en actitudes intelectuales. "La Loie" era, desde aquel momento, el prototipo de la fidelidad al espectáculo

Vinieron los daguerrotipos, los viajes, las ofertas, los epigonos y las imitadoras. También los celos profesionales con las divas del momento. Pero "La Loie" se echaba a la bolsa atenciones y reconocimientos: su larga trayectoria salvaguardaba el principio de sus esfuerzos: la trascendencia es la praxis honesta y consciente del talento. El teatro, como todas las grandes realizaciones del hombre, es a la vez pasión y sabiduría. Muchas de sus imágenes, fosforescencias, todos sus recursos visuales y técnicos surgieron de búsquedas para y ante el público. Sus descubrimientos la hicieron sufrir lo indecible al grado de que en una ocasión, al explotar las sales con las que experimentaba en su laboratorio, perdió toda su cabellera. Los vecinos, fascinados, comenzaron a llamarla "La bruja". Y en parte una hechicera luminosa fue esta mujer que por la vía del teatro más accesible, del vaudeville y del music-hall abrió la brecha de muchos de los espectáculos que hoy nos sorprenden y nos dejan con la boca abierta. Ángel, mariposa, flor en movimiento, camafeo volátil, luz exótica, desintegradora del "espeso espacio", "La Loie" hizo de las suyas con ingredientes que antes que ella ningún ser humano se había atrevido a combinar dentro de un escenario.

Junto con Maud Allan (1883-1956) Loie Fuller representa, entre los precursores de la danza moderna, una auténtica "ala popular" del género Su figura combina profundamente las dos raíces que dan origen a la danza moderna: una libre actitud técnico-estética con respecto a los cánones impuestos durante varios siglos por el ballet clásico y la correcta incorporación de los elementos teatrales (escénicos, de organización, efectos imaginativos, etcétera) y populares de la época. Los años que le tocaron vivir es el primer elemento vital en la biografía de la Fuller. Sin embargo, para el desarrollo y la historia de la 
danza moderna, cuentan, sobre todo, la imaginación de esta artista y su enorme amor por las artes escénicas. Una revisión de sus actitudes y de los sucesos en los que participa, muestra con claridad la callada aportación de la que resulta deudora la danza moderna. Como se dijo antes, Fuller nació, según algunas fuentes, en 1870; según otras, en 1862. Lo importante del hecho radica en las circunstancias: sus padres tuvieron que acudir a un bar para procurarse calor en una noche invernal El acontecimiento marcó a la artista para siempre pues tuvo una vida errante y desarraigada por tablados y tinglados teatra. les, por países en la que fue considerada una artista extravagante, por escenarios en los que hizo gala de una impresionante capacidad imaginativa. Además, ese frío inicial, nada simbólico, de mil maneras la obligó a buscar, a lo largo de estructuras y mecanismos teatrales, un elemento fundamental: la luz, luente de todo calor (Otro dato curioso: se hizo acompañar por su madre durante todas sus giras y presentaciones hasta la muerte de su progenitora)

Ignorante de los avances que lograba en el desarrollo de los implementos y procedimientos técnicos, Loie Fuller se consideró siempre una "mujer de tablas" Esta actitud de inconsciencia con respecto a sus propios logros (por lo menos al conocimiento de la dimensión de sus innovaciones) la hace gemela de Isadora Duncan. En efecto, aunque Duncan precisaba su oposición militante a las reglas del ballet clásico, jamás estableció metodológicamente la profundidad de los cambios que sus ideas y ejecuciones propiciaban en el mundo de la danza Fuller, de manera parecida, revoluciona los "modos" de una presentación teatral y aplica recursos creativos que con el tiempo tendrían efectos monumentales y colectivos. Es, en última instancia, una fanática de la danza-espectáculo Sin embargo, a diferencia de Isadora (para quien el cuerpo humano, su naturalidad y esencia constituían los elementos fundamentales, si no únicos, de la danza), Loie Fuller consideraba que la técnica y la ciencia, asi como la sencillez de los movimientos dancísticos, eran parte integral de un todo conformado por el fenómeno "espectáculo". Para ella, las bailarinas eran "instrumentos de la luz"3 pero inmersas siempre en un mundo sumergido a partir del escenario. Isadora Duncan bailó en la compañía de Loie Fuller durante una gira de esta última por Alemania pero la presencia de Duncan en el espectáculo duró poco pues le fue ofrecido un contrato para actuar en la ciudad de Budapest. A pesar de las diferencias conceptuales y prácticas en torno al arte dancístico, Duncan reconoció siempre la calidad enorme de Fuller y la distinguió de sus numerosas imitadoras

Desde el punto de vista sociológico, Loie Fuller experimenta y "padece" los embates de la vida del show buszeness, de manera análoga a la que décadas más tarde sufririan en carne propia estrellas del teatro y del cine como Marilyn Monroe A pesar de su enorme talento, de su ingenio, de los grandes creadores

3 Véanse: Clare de Morinni: "Loie Fuller", en Paul Magriel (ed): Chroncles of the American Dane From the Shaher to Martha Graham, Da Capo Press Inc, New York 1978 y Don MlcDonagh: The (omplete (sule to Kodem Damu, Doubleday and Co. Ine, New York. 1976 
que intentaron permanecer cerca de ella, la Fuller jamás se sintió satisfecha. No sólo trabajó obsesionada por la representatividad, la alegoría y el simbolismo suscitados por la luz de las artes escénicas sino también por la superenergía implicada en las actividades dancísticas y teatrales. Tal vez fue esta entrega desmedida a la organización y presentación de sus espectáculos la que impidió que se percatara de la importancia de sus descubrimientos. Aunque hablaba de "ciencia"; a pesar del numeroso conjunto de sus auxiliares en los menesteres de la iluminación, el sonido y la representación; no obstante la admiración y el respeto que sus realizaciones causaron en personalidades científicas como los Curie y Flammarion, Loie Fuller no se satisfizo tanto en la conciencia de sus logros ni en los regodeos del éxito sino que supeditó su forma de vida a la más auténtica corriente del show business, al grado de que resultó protagonista de no pocos escándalos en las sociedades europea y norteamericana de su época. Intensa, alocada, firme, violenta a la manera de posteriores estrellas de Hollywood, la Fuller prescinde de la sofisticación y el lujo para "vivir su vida", hacerse de sus propios recursos e instalaciones y para actuar en los escenarios y en la vida real libre de las ataduras que impone la sociedad burguesa en el mundo occidental. Tal es su afán por asumir las consecuencias de esta visión de la realidad, que durante la primera Guerra Mundial actúa en los frentes de batalla. Una vez terminada la conflagración, encauzará sus energias a coadyuvar a la presentación de grandes espectáculos operisticos y teatrales.

Poco después de su muerte por pulmonía, acaecida en 1928, el arte de Loie Fuller vino a considerarse anticuado junto con otro tipo de manifestaciones artísticas de la época. Sin embargo, sus innovaciones escénicas han influido notablemente en las aportaciones y logros de coreógrafos, realizadores, directores y cineastas posteriores. Asimismo, su concepción de la danza ha traspuesto la mera experimentación y quedado depositada en muchas producciones de los años actuales.

\section{7: Lote Fuller en México}

La prensa mexicana de la época se sorprendió gratamente con la presencia en el país de Loie Fuller A la bailarina norteamericana ya se la conocia por referencias de la prensa mundial. En efecto, La serpentina era una pieza que la Fuller habia bailado en Europa y los Estados Unidos y en la que tanto los efectos luminosos como la propia interpretación atraían gratamente a todo tipo de públicos El 12 de enero de 1897 El Universal da fe de la llegada a la Ciudad de México, por ferrocarril, de la artista norteamericana. La Fuller queda detectada, sobre todo, como creadora del baile La serpentina. Después de exponer datos sobre los primeros años de vida artística de la Fuller, el cronista de $E l$ Universal relata cómo surgió su originalísimo estilo:

Por el año de 1891 y de una manera casual fue como descubrió el baile que pronto después debía darle fama universal. Una noche que trabajaba en el 
Teatro del Casino de Nueva York, uno de sus admiradores le envió como obsequio una caja que contenía una exquisita tela del Japón que era de una transparencia y finura inigualables; la Loie que se estaba cambiando traje, quiso juzgar del efecto del obsequio sobre su cuerpo, y al hacer algunos movimientos casuales frente al espejo, vio que la tela adhiriéndose a su cuerpo le daba un aspecto fantástico, y en ese momento nació en su mente la idea de crear un baile en el que pudiera sacar partido de su descubrimiento.

El baile se vio por primera vez en el mismo Teatro del Casino y el éxito fue sorprendente; el público acudia en masa a admirar a la 'Serpentina', la que es una escultura por sus bellas formas y que, vista a través de la vaporosa tela y con los efectos que la luz eléctrica producía sobre la misma, parecía una hada de los cuentos árabes. ${ }^{4}$

En efecto, la pieza habia causado sensación en los Estados Unidos y está corroborado que se ideó de esta manera improvisada. Sin embargo, la Fuller ya habia experimentado anteriormente algunos juegos luminosos en la escena, pero no había llamado suficiente atención, al grado de casi autoconvencerse de regresar a sus trabajos como actriz. Fue el propio director del Casino, ante quien realizó la Fuller una audición, quien bautizó la pieza y quien tuvo la buena fortuna de percibir los atractivos del espectáculo.

También en 1891 Loie Fuller había viajado por varios países europeos y actuado ante presidentes y gobernantes. Al llegar a México, Mr Stevens, empresario de la artista, decla ró que se presentaría en el Teatro Nacional "en combinación con la compañía de zarzuela de los hermanos Arcaraz" y así lo anunciaba el cronista:

La temporada principiará el día 14 de éste y la Serpentina sólo se presentará aquí cinco veces al público, pues tiene que salir inmediatamente para el sur de los Estados Unidos, adonde ya tiene varios contratos pendientes; de alli irá a Australia y luego a China, el Japón y otros puntos de Asia.

La reconstrucción de la coreografía de la Fuller ha sido hecha por un investigador norteamericano de la siguiente manera:

La bailarina aparece sobre un escenario oscuro llevando un largo vestido de seda ceñido a la cintura que cae sobre el piso. Una banda circular ondulante rodea a la vestimenta en su extremo inferior y otra similar queda cerca del cuello. De repente los pliegues del vestido comienzan a ondular y expandirse y surgen rayos de luz desde la misma bailarina. Ella sostiene los extremos del vestido a la altura de los hombros y con movimientos rápidos y circulares crea cascadas luminosas. El espectáculo se convierte en una móvil masa dinámica. Se mueve de un lado a otro, siempre bañada por la luz y

HI lmarral. 12 de enero de 1897 
luego, dando la espalda, vuelve la cabeza en dirección del público y la parte superior de la vestimenta se asemeja a una flor que circunda su torso, cuando un momento antes aparecía como una alada mariposa... ${ }^{5}$

El mismo investigador acota que Serpentina era solamente la primera de una docena de danzas que Fuller había creado utilizando enormes volúmenes de tela ligera y aplicando los juegos de luces más imaginativos que se habían visto en los escenarios norteamericanos hasta esa época Afirma que la bailarina jamás había intentado narrar una historia sino que había creado piezas con un sentido lírico. Poseía la Fuller la capacidad de imitar los fenómenos físicos, sobre todo las figuras de flores, insectos y sucesos atmósfericos. Asimismo, la artista siempre permanecía a la vanguardia en los aspectos técnicos de los espectáculos y alcanzaba una mayor nitidez y una mayor perfección que los esfuerzos de sus imitadores. Finaliza el investigador recordando que la Fuller fue llamada "La creatura de luz", denominación que resumía las cualidades creativas y artisticas de Loie Fuller.

Puede apreciarse que la capacidad de organización técnica del espectáculo era otra de las cualidades de la artista norteamericana. Entre los datos que ofrecía el empresario a la prensa mexicana de 1897 acerca de los sitios a los que viajaba la bailarina, se cuentan detalles que en general no se hacen públicos en las compañías de danza. Así, el cronista ofrece los siguientes detalles:

La Loie viaja con todos los aparatos que necesita; que son de su propiedad y muchos de ellos de su invención; la acompañan siempre doce empleados, siendo tres de ellos ingenieros electricistas.

Para los efectos de luz que se necesita producir en los bailes, va a haber necesidad de quitar parte del piso del foro substituyéndolo con cristales.

Para el 15 de enero, o sea tres días después, la Fuller había ejercitado toda su simpatía con "los chicos" de la prensa. En una entrevista publicada en $E l$ Universal el cronista ofrece datos curiosos, por ejemplo el hecho de que Loie Fuller viaja "acompañada de la señora su madre, que nunca se aparta del lado de su hija". La tradicional cortesía mexicana había logrado que un grupo de artilleros le diera una serenata en el patio del hotel, hecho que había dado pábulo a un gracioso incidente:

Al llegar la banda a las órdenes de su segundo director salía el príncipe de Juevennuller del hotel y como los músicos creyeran que se les habia enviado para que tocaran en honor del huésped austriaco, ya se disponían a retirarse, cuando llegó el primer director, señor Capitán Pacheco y se aclaró el error $^{6}$

${ }^{5}$ Don McDonagh, Of, cit, p 21

'Ll L mierval, 15 de enero de 1897 
Loie Fuller se sentía encantada. Según la crónica permaneció departiendo con sus admiradores hasta bien entrada la noche, escuchando "extasiada los aires de la banda que en su honor había sido enviada. Según la reseña, hizo comentarios sobre diversos temas musicales ya que el cronista la cataloga como "una gran admiradora de la buena música" y la artista, al referirse a una pieza titulada "No existe ningún lugar como la patria" ar gumentó que la encontraba aquí, en México, por la forma amáble en que sus seguidores là recibieron. Esa misma noche la Fuller firmó autógrafos y recibió una medalla, también regalo de los mexicanos. Tan entusiasmada se sintió la artista que bajó de sus habitaciones su consabido álbum de autógrafos "e hizo que el Capitán Pacheco pusiera el suyo en la misma hoja en el que está el del maestro Verdi, el insigne autor de Aida". También habian firmado este álbum muchos gobernantes, inventores, científicos y artistas.

Al retirarse la banda la Loie mandó que los filarmónicos fueran obsequiados con cerveza, cognac, champagne, pasteles y sandwichs, y que se les dieran pases para su primera presentación en el Teatro Nacional, que será en la noche de hoy.

La personalidad de Loie Fuller no queda explicada completamente con estos rasgos de simpatía y con su inteligente proceder cuando entraba en contacto con la prensa y con el público que la requerian. La Fuller fue amiga y entabló relaciones amistosas con técnicos, científicos y artistas de su época. Curiosamente, los procedimientos que aplicaba en su trato con "los chicos" de la prensa eran similares a los que utilizaba para congraciarse con gente tan seria como los científicos. Se cuenta que cuando la Fuller supo del descubrimiento del radio por los esposos Curie, se apresuró a escribirles una carta que María Curie calificó de "naif". Se había dado a la publicidad el hecho de que el radio emitía una pálida y mágica luz que irradiaba a partir de un trozo del mismo elemento. Esto llamó la atención de la artista y pensó que podría utilizarse para lograr un efecto dancístico Eva Curie relata que la Fuller escribió para recibir información al respecto porque quería "alas de mariposa de radium". Naturalmente, los esposos Curie le explicaron amablemente que este tipo de efectos resultaba inalcanzable por el enorme costo que representaba. La respuesta de la Fuller no se hizo esperar: "sólo tengo una manera para agradecer el hecho de que ustedes me hayan contestado Permítanme bailar una noche en su casa ..." Los esposos Curie aceptaron el ofrecimiento de la artista pero quedaron sorprendidos cuando uñ nutrido grupo de electricistas llegó a la pequeña casa que habitaban y comenzaron a instalar numerosos implementos teatrales. A su llegada, la Fuller reanudó los arreglos técnicos para su presentación y llena de seriedad se gastó toda la tarde en los preparativos del inhabitual show. Por la noche regresó y actuó ante los esposos Curie, algunos amigos y los hijos de ellos: había logrado construir el tinglado completo que acostumbraba en el Follies Bergere. Los niños Curie, hijos del famoso matri- 
DOI: http://dx.doi.org/10.22201/iie.18703062e.1982.50\%20Tomo\%202.1148

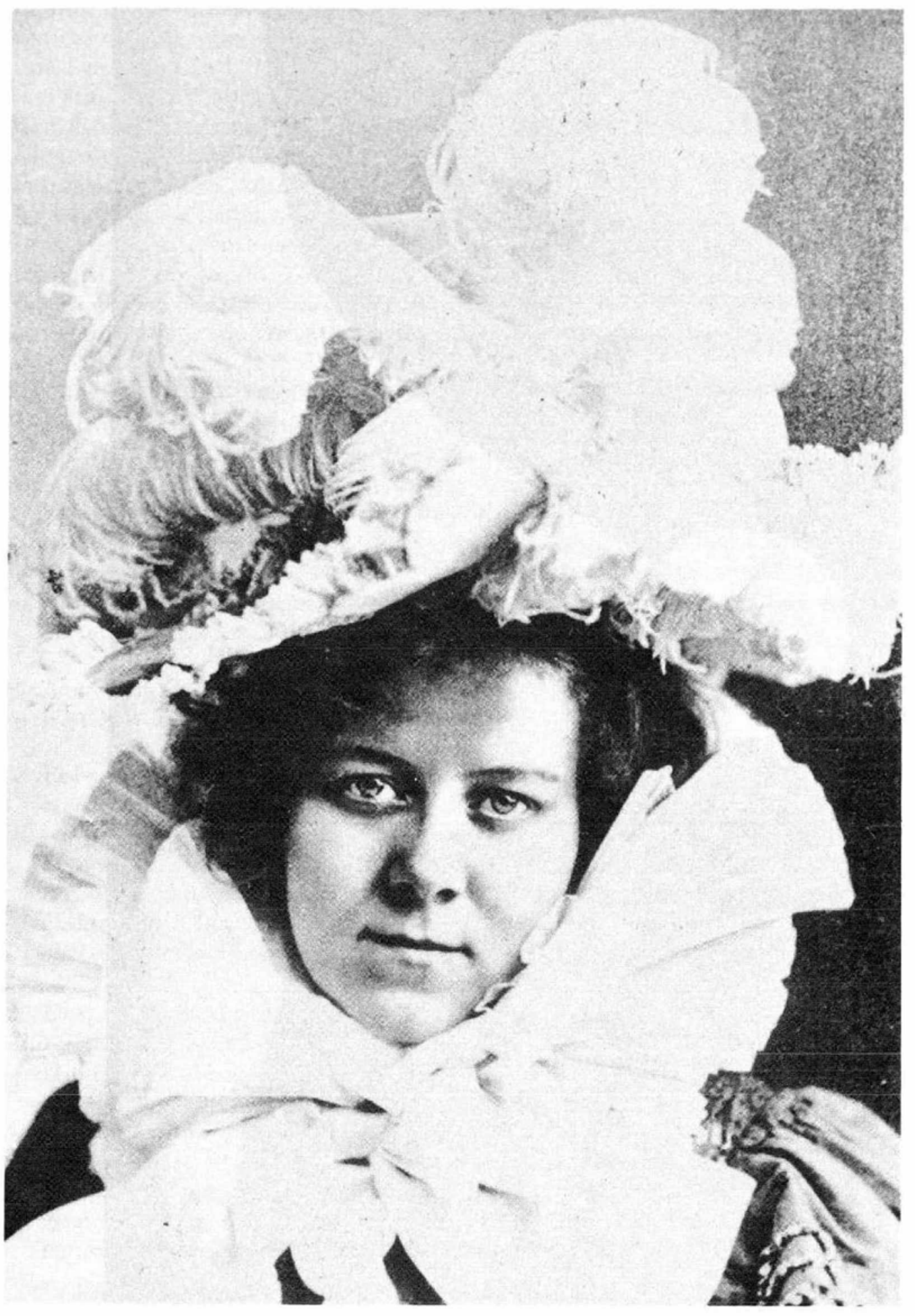


DOI: http://dx.doi.org/10.22201/iie.18703062e.1982.50\%20Tomo\%202.1148

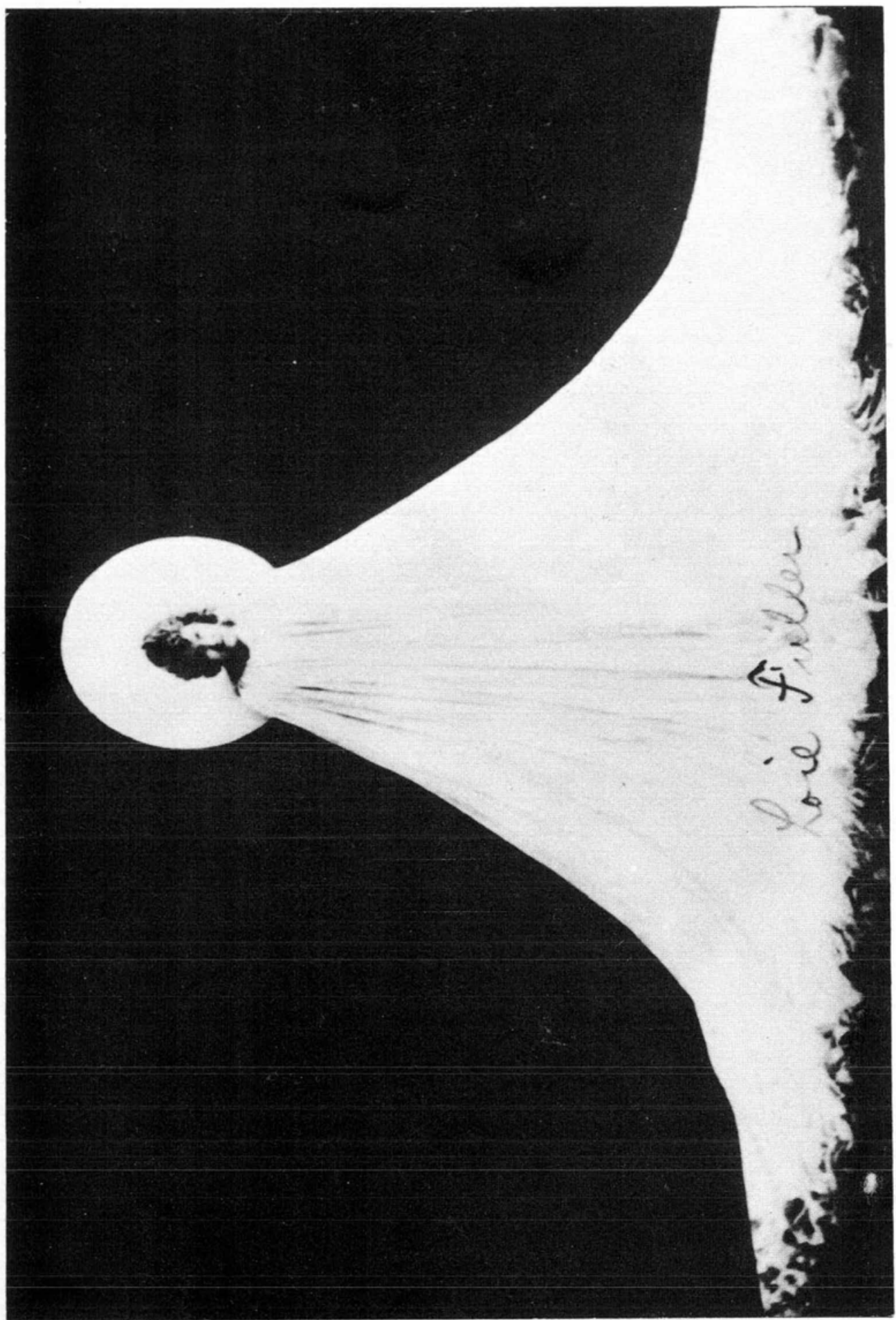


monio, no habrían de olvidar jamás el espectáculo y percibieron esas características de la personalidad de Loie Fuller que habrian de quedar resumidas en una frase de Eva Curie: "Loie poseía un alma delicada"?

Tanto por la calidad de su espectáculo como por su desenvuelta personalidad, Loie Fuller causó profundas impresiones en la prensa y en el público de México. El cronista de El Lniversal reconoce el jueves 21 de enero de 1897 que la bailarina había cautivado a la sociedad mexicana con sus for mas esculturales y con su "artística coreografia". Al dejar México, la Fuller habria de presentarse en San Antonio, Texas y en San Francisco, Califor nia para luego viajar por China y Japón. Ya el itinerario manifestaba la enor me fama adquirida por la Fuller Nostálgico, el cronista revelaba datos curiosos de la "notable bailarina", datos que mantendrían en la mente de los lectores la fulgurante figura de la artista norteamericana. A través de ellos podemos detectar, asimismo, algunas de las manifestaciones estéticas y de las costumbre: de los núcleos burgueses y artísticos de Europa y Norteamérica. Por ejemplo, la Fuller, según el cronista, escogía la ciudad de Niza para veranear.

En esa ciudad el año próximo pasado la Loie tomó parte en el legendario 'combate de las flores' y obtuvo el primer premio por su elegancia y refinamiento. La Loie iba dentro de una concha for mada por camelias blancas y violetas alpinas y sobre un palanquín que llevaban cuatro negros vestidos de pajes y que lucían los colores americanos (su)

Acerca de las ganancias económicas logradas por la Fuller por sus actuaciones en México, el cronista afirma:

Loie Fuller, contratada por los hermanos Arcaraz, tenía el cuarenta por ciento sobre sus utilidades. Ganó cinco mil pesos y gastó cuatro mil en alhajas en varias joyerías en esta capital. Tuvo algunas dificultades, pues estando acostumbrada a las fáciles transacciones mercantiles de los Estados Unidos y teniendo un sólido crédito, se encontró con que algunos de los comerciantes de la capital no querían admitir los checks que la artista daba contra el 'New York State Bank'.

Después de describir el "maravilloso guardarropa" de la Fuller, el cronista dio fe de la aguda inteligencia de la artista relatando cómo noches antes de su partida preguntó a dos funcionarios públicos:

¿Qué proporción creen ustedes que guarde la criminalidad de México con la de mi pais?

Y como los funcionarios, pagados por la nación y que debían saber eso, guardaron ignominioso silencio, 'La serpentina', mejor instruida que ellos, contestó: Pues señores, según las estadísticas que he visto, en México, rela-

7 Clane de Morini of ,ll. p. 213 
tivamente a su población, se comete un cincuenta por ciento menos de crímenes que en los Estados Unidos.

Los comentarios huelgan.

Asimismo, el cronista hace referencia a una entrevista que jamás pudo efectuarse entre la Fuller y doña Carmen Romero Rubio de Díaz, así como a la promesa de la artista norteamericana de ofrecer una función especial de beneficiencia en México.

Cada día los criterios para situar el origen de la danza moderna se acercan en mayor medida a las artes del espectáculo que a los meros conceptos. En este sentido, la figura de Isadora Duncan tiende a opacarse y surgen de manera más viva y brillante las personalidades de Loie Fuller, Maud Allan y Ruth St. Denis La primera, sobre todo, parece monopolizar intereses que anteriormente se hallaban en estado de latencia, toda vez que los investigadores y críticos de la danza intentaban explicarse el fenómeno desde la perspectiva conceptual y no a partir de los hechos dancísticos que realmente dieron lugar al movimiento.

En efecto, incluso la aparición artística de Loie Fuller contiene ingredientes que habrán de repetirse a lo largo de la historia de los espectáculos de revista en los Estados Unidos. Simbólicamente, el acontecimiento parece vincular el mundo del show business con un estado anímico colectivo. Así, Loie Fuller aparece en una época en la que la expansión comercial de los espectáculos de Norteamérica requería de una rápida y abierta aceptación moral de sus piezas, de sus números, de sus modalidades. Es precisamente la época de la que arrancará la tradición del espectáculo norteamericano, en un país y en un momento histórico en que cualquier referencia a los "logros" anteriores hubiera significado el descubrimiento de una ausencia total de elementos culturales nativos, a no ser que aludiera a las entonces discriminadas expresiones negras. El arte del espectáculo en esta época se arraiga a su origen y propugna por un arte netamente norteamericano. Sólo en el reconocimiento de este punto de partida pueden entenderse las afirmaciones del crítico Clive Barnes en el sentido de que el jazz y la danza moderna son las únicas formas artísticas nativas de los Estados Unidos. ${ }^{8}$

En estos parámetros históricos la aparición y la figura de Loie Fuller se agigantan tras un somero análisis: su vida "extravagante", su entrega total a las artes escénicas, su increible inventiva técnica la hacen demasiado atractiva e importante. No puede el teórico o el crítico pasarla por alto: al igual que Isa. dora, ella también bailó descalza y acabó por incorporar la música sinfónica

${ }^{8}$ Clive Barnes en Anne Livet (ed ): Contemporary Dance, Abbe Ville Press, Inc, New York, 1978 
al arte coreográfico Su trayecto como actriz y cantante le permitió, antes de penetrar en la danza, satisfacer los requerimientos-conocimientos fundamentales para realmente "experimentar" en el escenario

Loie Fuller comienza su vida artística con un suceso que combina precisamente la frivolidad propia del teatro de revista con la necesidad de incluir el elemento religioso que el business exigía en aquella época. Así, si aceptamos que a la edad temprana de dos años y medio irrumpe en el escenario donde actuaban sus padres y recita "inspirados versos religiosos" aceptamos de lleno que la expansiva clase media norteamericana requería elementos que legitimaran espectáculos que antes se consideraban "vulgares" o pecaminosos. Muchos años más tarde la historia habrá de repetirse en el surgimiento de otras figuras de los escenarios norteamericanos pero sobre todo el fenómeno se convertirá en la leyenda que al fin corrobora una idea básica y, sobre todo, válida para el enorme desarrollo del espectáculo en los Estados Unidos: el teatro, la danza, el show business, la actuación cinematográfica, el "estrellato" son una forma de vida. Todo lo cual significa que el país entraba ya en una época de franca especialización, de una especializadísima división social del trabajo.

9 Don Mcl)onagh: (pp. all, p. 20 